\title{
Morbidity and mortality on combination versus monotherapy: a posthoc analysis of the Systolic Hypertension in Europe trial: Erratum
}

The authors of the article published in issue 4 of volume 28 [1] would like to correct Figures 4 and 5, which have been published incorrectly.

The axis x should have read: years instead of: months as presented in figures below.
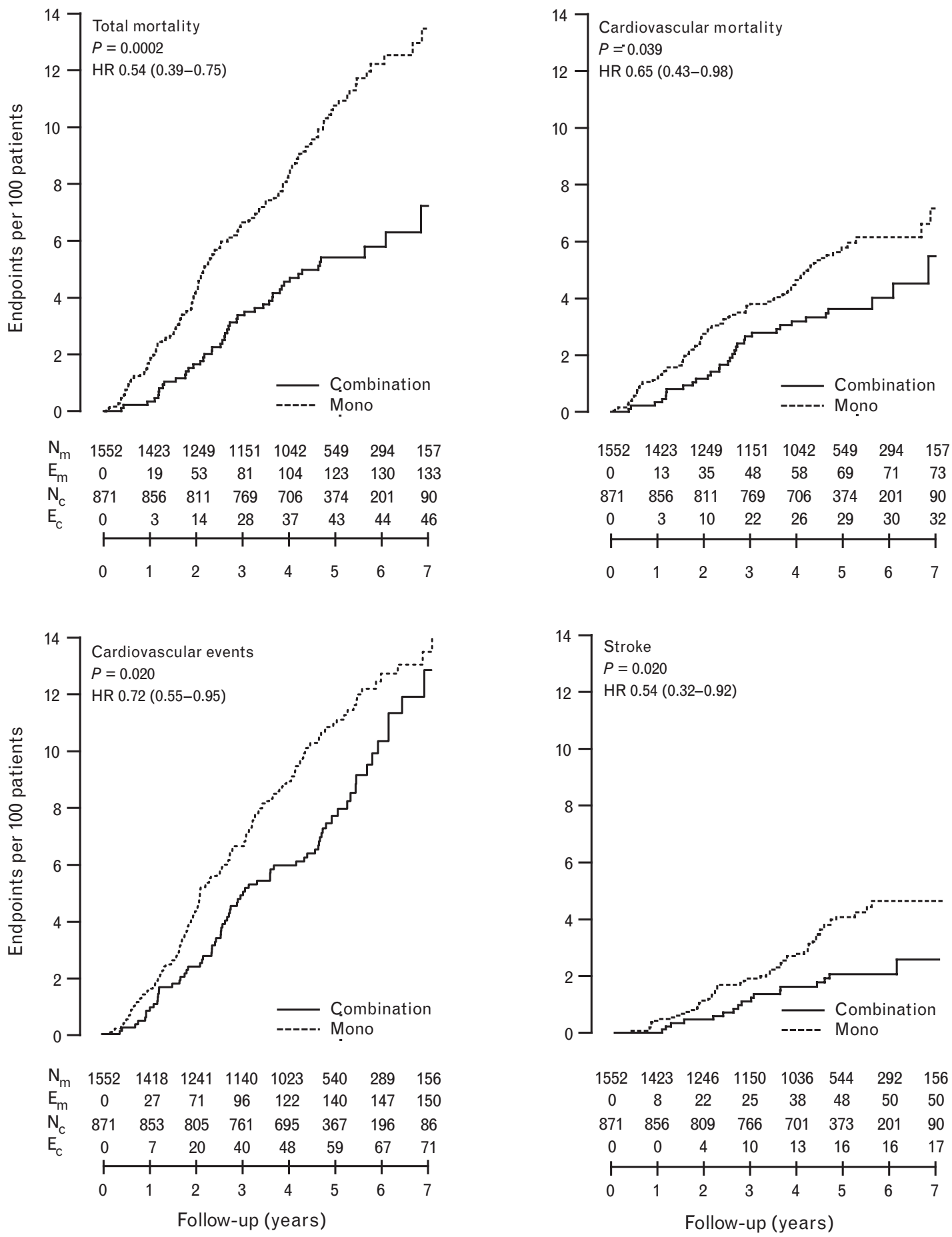

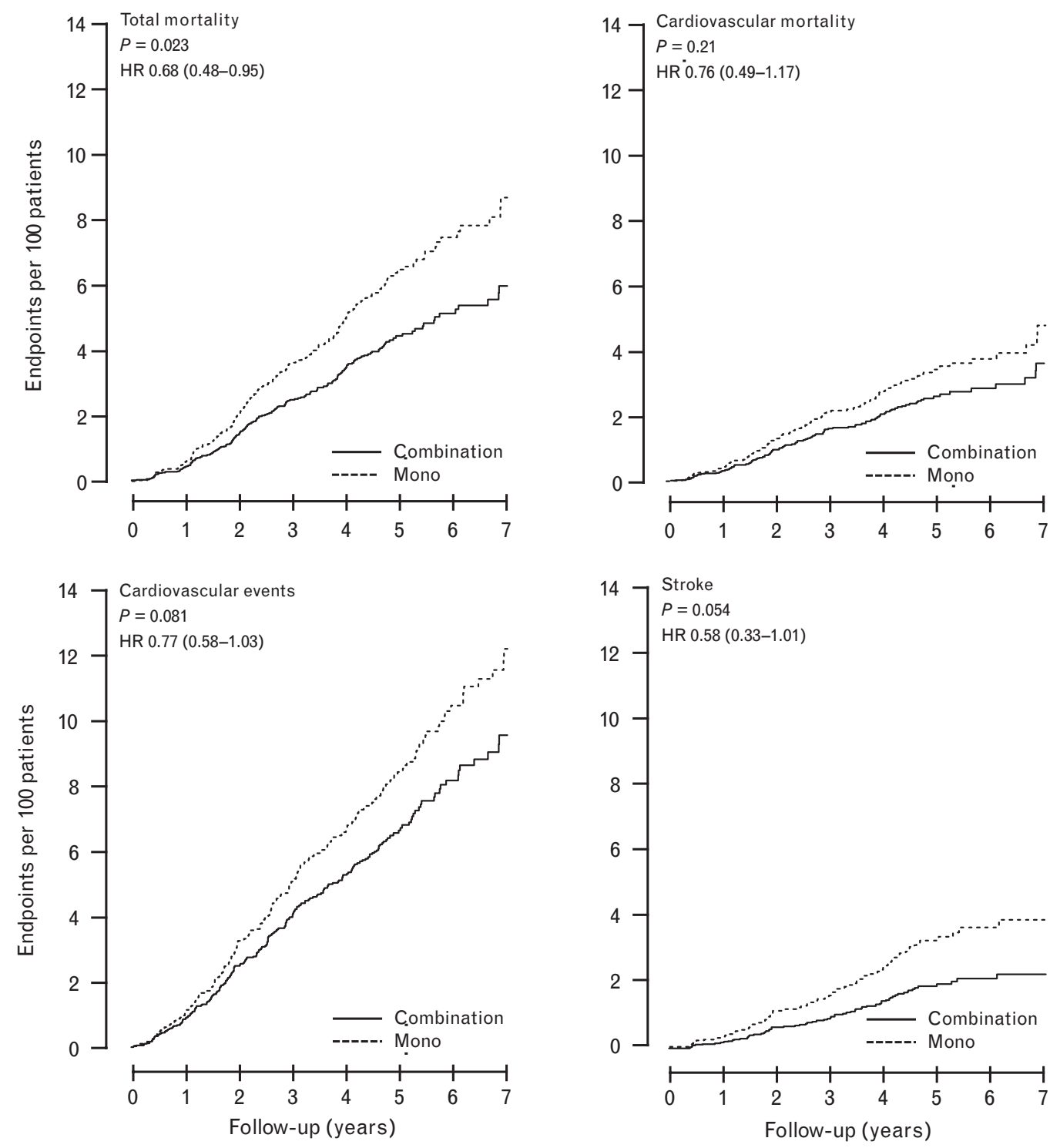

\section{Reference}

1 Thijs L, Richart T, de Leeuw PW, Kuznetsova T, Grodzicki T, Kawecka-Jaszcz K, et al. Morbidity and mortality on combination versus monotherapy: a posthoc analysis of the Systolic Hypertension in Europe trial. $J$ Hypertens 2010; 28:865-874. 